Resumo

Este trabalho foi concebido a partir da temática sobre o brincar e o estatuto da fantasia, eixo teórico da AP3. Propõe-se o brincar como via de elaboração de uma versão particular acerca dos significantes relacionados à construção do próprio corpo da criança, ao seu Outro e ao mundo que a ela se apresenta, assim como expressão da posição da criança como sujeito em constituição e mesmo sujeito que (já) é. Em sua relação com a fantasia - ou como via de expressão fantasmática -, o brincar viabiliza processos de representação e, paradoxalmente, aponta para algo que resiste a ser representado, mas que continua a atuar no psiquismo.

Descritores: brincar; fantasia; desenvolvimento infantil; indicadores clínicos.

\section{CONSIDERAÇÕES ACERCA DO BRINCAR E DO ESTATUTO DA FANTASIA A PARTIR DE PROPOSIÇÕES TEÓRICAS QUU BASEIAM A PESQUISA IRDI}

\section{Situando a pesquisa multicêntrica Indicadores de Risco para o Desenvolvimento Infantil (IRDI)}

$\mathbb{4}$ ste trabalho foi concebido a partir da temática sobre o brincar e o estatuto da fantasia, eixo de análise que compõe a avaliação psicanalítica aos três anos de idade (AP3), sendo que se faz necessário, desde já, pontuar que nosso propósito não é apre-

Psicóloga, mestranda do Programa de Pós-graduação em Psicologia Escolar e do Desenvolvimento Humano do Instituto de Psicologia da Universidade de São Paulo.

- Psicóloga, mestranda do Programa de Pós-graduação em Psicologia Clínica do Instituto de Psicologia da Universidade de São Paulo. 
sentar uma investigação sobre o brincar e sobre a fantasia, visto que, em sua condição de conceito, cada um guarda a devida complexidade dentro do campo psicanalítico, mas sim pensar na intrínseca relação entre ambos.

A AP3, ou avaliação psicanalítica aos três anos de idade, configura-se como um instrumento diagnóstico, construído com o objetivo de comprovar a fidedignidade de outro instrumento, o IRDI (Indicadores de Risco para o Desenvolvimento Infantil). Tais instrumentos - AP3 e IRDI - foram criados para sustentar o projeto de pesquisa intitulado "Leitura da constituição e da psicopatologia do laço social por meio de indicadores clínicos: uma abordagem multidisciplinar atravessada pela psicanálise", mais conhecido por "pesquisa multicêntrica de indicadores clínicos de risco para o desenvolvimento infantil", ou mesmo, “pesquisa IRDI" (Kupfer et al, 2009).

Como referido, o projeto que sustentou a pesquisa IRDI buscou validar, a partir da teoria psicanalítica, a leitura da constituição e da psicopatologia do laço social por meio de indicadores clínicos de risco para o desenvolvimento infantil (IRDIs) observáveis nos primeiros 18 meses de vida da criança. Tais indicadores poderiam ser traduzidos por comportamentos precoces da criança e também de interação com seu cuidador e com os demais sujeitos de seu entorno.

Os indicadores foram uma contribuição da prática clínica de alguns psicanalistas de crianças ${ }^{1}$ - inclusive os que atuam em clínica com bebês , que já vinham observando e registrando sua presença ou sua ausência nesses momentos primordiais para a constituição psíquica.

A necessidade de traduzir esses indicadores por comportamentos observáveis deu-se justamente porque um dos objetivos da pesquisa foi construir um instrumento que pudesse ser utilizado por pediatras e por profissionais de saúde da atenção básica.

A pesquisa IRDI se utilizou de um desenho de corte transversal seguido por estudo longitudinal numa amostra de 726 crianças atendidas na clínica pediátrica das unidades e/ou centros de saúde em nove cidades brasileiras (totalizando onze centros). Após três anos de seu início, as crianças participantes foram submetidas a avaliações psicanalíticas e psiquiátricas. Essas, por sua vez, tiveram por objetivo identificar transtornos psicopatológicos que pudessem ter algum tipo de associação com os indicadores (IRDIs). Ou seja, aos três anos de idade, avaliavam-se as crianças com outro instrumento (AP3 - Avaliação Psicanalítica aos três anos de idade) no intuito de fazer correlações entre algum indicador e alguma possibilidade - ou ausência - de manifestação psicopatológica atual. Essas avaliações foram finalizadas em 2007.

Assim, podemos considerar que o instrumento AP3 configurou-se como um meio de comprovação da fidedignidade do instrumento IRDI, 
mas não somente, já que o próprio instrumento AP3, isoladamente, apresenta-se como um importante instrumento diagnóstico para detecção de psicopatologias precoces incipientes ou mesmo em curso. Se o valor do instrumento IRDI é preventivo, o instrumento AP3 caracteriza-se como instrumento diagnóstico.

A partir dos resultados das avaliações psicanalíticas (AP3) foi montada uma tabela de sintomas clínicos, definindo-se, em seguida, o desfecho clínico da pesquisa através: a) da presença ou da ausência de problemas de desenvolvimento para a criança, ou b) da presença ou da ausência de risco para a constituição do sujeito. Tal desfecho pôde ser construído através das seguintes categorias de análise: a) o brincar e a fantasia; b) o corpo e sua imagem; c) manifestação diante das normas e posição frente à lei; e d) a fala e a posição na linguagem (Kupfer et al, 2008).

Consideramos, então, que é tanto por seu valor diagnóstico como também por certo ineditismo quanto aos eixos teóricos psicanalíticos que a AP3 se destaca no próprio contexto da pesquisa IRDI.

Sabemos que cada categoria de análise presente no instrumento AP3 guarda em si uma complexidade, o que pode gerar vários outros desdobramentos. Contudo, foi no decorrer das entrevistas que observamos que especialmente o brincar expressava mais que fantasias inconscientes, mas também as formulações singulares 
que cada criança construía sobre si, sobre sua família e sobre o mundo cada vez maior e mais complexo que estava a conhecer.

Entendemos que o brincar, mais do que revelador de uma história ou de um sintoma, estaria a serviço da própria construção da história da criança. Giongo (2005) propõe que o brincar estaria a serviço da narrativa na análise com crianças, sendo que a própria possibilidade de brincar - "Vamos fazer de conta?" - já marcaria um processo de diferenciação eu-outro e eu-mundo a ser construído por esse sujeito em constituição.

\section{A importância do brincar no campo teórico- clínico que fundamenta a AP3}

Pensamos que, para situar a importância do brincar a partir das perspectivas teórico-clínicas que fundamentam a AP3, temos de referenciá-lo quanto à:

\section{1 - sua relação com a fantasia}

Jerusalinsky (2008) considera que "há uma diferença fundamental entre o adulto e a criança que faz com que nesta o imaginário ocupe uma posição privilegiada: a de constituir o lugar de ensaio e de antecipação do que ainda está por vir" (p. 125).

É assim que, dessa perspectiva, a fantasia ocupa um lugar no psiquismo infantil que se torna tênue para a criança, o limite entre a própria fantasia e a realidade. $\mathrm{O}$ autor ainda aponta que no adulto neurótico normal, podemos encontrar "a fantasia subjetivada sob a forma de ficção, onde a ordem simbólica corta de modo muito mais nítido o limite entre o imaginário e o real" (Jerusalinsky, 2008, p. 125). Assim, propõe o autor: "Na psicopatologia da infância cumpre um papel relevante para o diagnóstico, precisamente, a posição desse imaginário. Tal razão, por exemplo, do papel protagonista que o brincar teve, e ainda tem, na Psicanálise de crianças. É também esse o fundamento de que, de um modo geral, a proposta de entrevistas diagnósticas, em Psicanálise de crianças, seja realizada através de uma ou mais 'horas de jogo'. É, certamente, uma forma de permitir a expressão do imaginário de um modo livremente associativo para revelar a posição da fantasia no inconsciente desse sujeito infantil." (Jerusalinsky, 2008, p. 126). 
Desse modo, durante a avaliação psicanalítica, o brincar ocupou posição tão importante quanto o discurso, sendo uma expressão por excelência das significações construídas pelas crianças.

"A fantasia, a apreensão da dimensão da fantasia, ela está na própria origem, no próprio nascimento da psicanálise", assim Jorge (2007, p. 143) concede à fantasia o estatuto fundador da psicanálise, na medida em que ela nasce no momento mesmo em que Freud abandona a teoria da sedução e do trauma, que o acompanhou durante algum tempo.

É no momento em que Freud (1897/1996a) se despoja da teoria traumática na etiologia das neuroses que se abrem as portas para o reconhecimento gradual da sexualidade infantil como um evento "universal" (amplamente trabalhado em seus Três ensaios sobre a teoria da sexualidade, de 1905) e para o desempenho da fantasia, capaz de "atuar com toda a força das experiências reais" (Freud, 1897/ 1996a, p. 303).

Garcia-Roza (2000) lembra que a Carta 69 é frequentemente apontada como expressiva de um momento fundamental do pensamento freudiano: "o da passagem para a fantasia, lugar por excelência da cena psicanalítica” (p. 95). Avançando alguns anos em sua obra, veremos a relação da fantasia com o brincar infantil e com a criação literária.

Em dezembro de 1907, nos salões do editor e livreiro vienense
Hugo Heller, Freud apresenta uma conferência diante de uma plateia de noventa pessoas. Nela, esboçava-se a aproximação entre a fantasia e o brincar infantil. O brincar seria um trabalho psíquico onde o conteúdo essencial é a realização imaginária de um desejo, tarefa levada muito a sério pela criança e de fundamental importância para seu desenvolvimento, como lembra Toledo (2003). A fantasia do adulto seria a formação de um substituto desse brincar, pois "nunca renunciamos a nada; apenas trocamos uma coisa por outra. ... a criança em crescimento, quando para de brincar, só abdica do elo com os objetos reais; em vez de brincar, ela agora fantasia" (Freud, 1907/1996b, p. 136, grifo original).

Em se tratando de um trabalho realizado com crianças, torna-se imprescindível considerar as dimensões do brincar e das fantasias subjacentes a esse processo. Parte-se do pressuposto de que o brincar é uma via de elaboração e, também, um indicativo de quando algo não vai bem no desenvolvimento infantil: a dificuldade em diferenciar os limites entre o faz-deconta e a realidade é um exemplo.

\section{2 - sua condição de via de elaboração ante a construção do laço social}

Em relação à construção do laço social, pode-se pensar que a questão psicanalítica fundamental seria a de se debruçar sobre a constituição do psi- 
quismo, que somente aconteceria a partir de relações muito precoces que a pequena criatura humana estabeleceria com seus semelhantes.

Sob a perspectiva psicanalítica, esses semelhantes - esses outros sustentariam uma função: a função de Outro $^{2}$, que se confundiria com a ordem da linguagem. Nesse sentido, o sujeito se constitui referenciado ao discurso social e, mais especificamente, "no ponto de articulação entre sua fantasia e o discurso social." (p. 9) Sobre tal questão, propôs Calligaris (1993, p. 16): “O inconsciente não é um depósito mnésico individual. Ao contrário, como Lacan diz, ele é transsubjetivo, ou seja, o inconsciente é a rede de laços de linguagem, os discursos que nos organizam e pelos quais somos produzidos como sujeitos. A cena analítica, o consultório de um analista, é um lugar povoado por uma multidão indefinida. Desde que o sujeito fala, articula-se uma rede que se estende indefinidamente, da qual ele é feito." (1993, p. 16).

É desse modo que a constituição do psiquismo humano encontrase intrinsecamente relacionada à construção do laço social que, por sua vez, seria aquilo que permite ao sujeito fazer um vínculo com a cultura, uma aliança com o universo simbólico que rege as relações humanas.

Assim, o sujeito não existiria fora desse campo - o da linguagem - posto que seria a própria linguagem criadora do mundo humano. Não haveria como pensar o sujeito fora desse 
enlace com o Outro - função transmitida e sustentada pelos outros semelhantes. E por meio desse enlace, desse discurso, o sujeito passaria a se relacionar com os significantes próprios da cultura à qual pertence.

A proposta da pesquisa IRDI se aproxima dessa perspectiva, uma vez que a constituição do laço no primeiro ano de vida dar-se-ia pela inserção da pequena criança na cultura e na linguagem, a partir das relações que ela estabeleceria com outro humano, geralmente a mãe ou o cuidador. A inserção da pequena criança na linguagem teria um alcance organizador das próprias funções orgânicas.

É interessante pensar, então, quão complexo pode ser o caminho que o pequeno ser humano terá de fazer para advir como sujeito. Ao mesmo tempo em que está construindo um corpo - uma imagem corporal -, precisa assimilar o encontro com a alteridade através de uma progressiva separação do Outro materno que, para acontecer dom modo menos desorganizador possível, precisaria estar precedida de uma fusão com esse Outro. Seria tal fusão que, segundo Molina (2001), possibilitaria ao bebê ser "cativado, seduzido, porém não capturado, escravizado" (p. 47).

Esse ser, ainda tão pequeno, já nasce ocupando um lugar no imaginário parental que, por sua vez, herda significantes transgeracionais e sociais. Rodulfo (1990) propõe que a pergunta pela criança conduziria à sua pré-história, em direção às gerações anteriores. Toda essa "multidão indefinida" 3 contribuirá com uma infinidade de significantes que edificarão uma história para a criança, construindo uma narrativa para o emergente sujeito e, fazendo, assim, uma função de antecipação.

Essa antecipação deverá, através de um outro desejante, ter um sentido de oferta, de suposição, jamais de imposição. Assim, para que a emergência de um sujeito seja possível, ele, a princípio, recolhe aquilo que lhe falam, contudo, como propõe Rodulfo: "O bebê tem de trabalhar e ainda lutar para adquirir significantes. As funções, parentais e outras, devem auxiliá-lo, fornecendo-lhe as condições mínimas, mas não se pode presenteá-lo com fatos; melhor dito, se houvesse imposição de significantes, se não se permitisse a ele achálos, falharia o essencial.” (1990, p. 35).

Para esse autor, a passividade não seria (ou não deveria ser), em momento algum, um atributo da infância. Ele propõe que o encontro com significantes que o representem deve ser a tarefa originária de um bebê, inclusive ressaltando essa dimensão da espontaneidade que, por sua vez, seria a tradução de uma posição ativa. É possível lembrar, então, da hipótese de Winnicott (1975) de que o bebê vai ao encontro do seio que lhe é oferecido como se o criasse e pensamos que isso tem um valor imprescindível para a possibilidade que o ser humano tem de criar o mundo, sentir-se parte dele. 
É importante essa palavra encontro, já que ressalta a função ativa da criança - como sujeito - em elaborar, de modo peculiar, os significantes que circulam. É habilidade imprescindível, para o sujeito humano, que possa transformar(-se), reconstruir(-se) como resposta às diversas demandas impostas no decorrer de sua vida. Assim, para transformar tais significantes, a criança brinca com eles e, por meio do brincar, tenta elaborar as marcas do encontro com o Outro.

Sobre tal questão, Rodulfo (1990, p. 79) chega a propor que "brincar é esburacar", no sentido de produzir buracos, rupturas nos significantes que serão transmitidos à pequena criança. É o que Giongo (2005) propõe ao supor que uma criança brinca com a narrativa que lhe foi concedi$\mathrm{da} /$ conferida por outros como uma tentativa de elaborar uma narrativa própria. A autora, inclusive, pensa na função de antecipação como uma "plataforma de passagem". Seria para ela: "um lugar de onde se possa partir, mas que também, em algum momento, possa desdobrar-se na construção de uma versão própria, numa apropriação singular destes significantes ofertados pelo Outro. Versão que na infância será construída no terreno do faz-de-conta, como uma história para brincar." (Giongo, 2005, p. 37).

Giongo (2005, p. 37) ressalta, contudo, que para que uma criança construa uma história no brincar, ela já deve ter demarcado a diferencia- 
ção em relação ao Outro "pois a possibilidade de acesso ao simbólico e, com ele, ao campo das representações, se funda nesta diferenciação".

Para Winnicott (1975), contudo, a diferenciação eu e não eu não teria limites estanques. Os vários sentidos construídos pelo sujeito e por seu Outro seriam intercambiáveis, mas o sujeito, contudo, sempre preservaria um sentido de si.

Pensamos, então, que o brincar tem esse valor de intercâmbio, de compartilhamento, mas o que vai ser compartilhado provirá do próprio sujeito, que está na cultura, que a partilha com seus semelhantes, mas que lhe atribui sentidos particulares. Ressaltamos, com isso, a proposição de Donald Winnicott: que o brincar também apresenta uma precariedade, no sentido de que parte da criança a criação de alguma coisa ante os elementos de seu mundo.

\section{Considerações finais}

A pesquisa IRDI fundamenta-se na concepção de sujeito tal como nos propõe a Psicanálise, em particular a partir da leitura de Sigmund Freud e de Jacques Lacan.

Uma abordagem psicanalítica da criança não pode deixar de considerar alguns aspectos fundamentais para sua constituição psíquica, quais sejam, aqueles que propiciam a emergência de um sujeito desejante. Acreditamos que a construção de um sujeito desejante acontece sempre a partir de um encontro entre o pequeno ser, em geral ávido pela presença de um outro humano, e o lugar que este outro confere ao bebê, mesmo antes de seu nascimento. O lugar ao qual nos referimos não é somente um quarto ou um berço, mas um lugar psíquico, uma posição subjetiva que vai se inscrevendo, paulatinamente, na (e pela) linguagem, na família e na cultura, em uma combinatória que construirá a sua história.

Consideramos, então, que a posição subjetiva a ser construída pela criança foi a questão clínica que permeou a pesquisa IRDI, configurando-se como sua questão central de pesquisa, o que, por sua vez, justificou a preocupação em elaborar indicadores que minimamente pudessem predizer, em um momento precoce, a inscrição de tal posição. Assim, esta pesquisa permitiu trabalhar com certos indícios que podem resultar em determinada posição subjetiva. $\mathrm{O}$

186 Estilos da Clínica, 2010, Vol. 15, n 1, 178-193 
trabalho preventivo clínico-institucional possível, quando se considera a prática psicanalítica, não se baseia exatamente em um prognóstico, mas, sim, na aposta, ou melhor, na sustentação da suposição de que o pequeno ser pode vir a ser um sujeito de seu próprio desejo. Portanto, é a capacidade de supor um sujeito que está em jogo quando se considera o valor preventivo dos indicadores.

O trabalho junto à Saúde Pública, contudo, exige uma maior objetividade por parte do conhecimento psicanalítico, e a pesquisa IRDI demonstrou que pode ser viável definir indicadores, observados na própria clínica psicanalítica, que auxiliem na detecção precoce de ocorrência de problemas do desenvolvimento infantil antes que eles se cronifiquem e, consequentemente, na possibilidade de apontar tratamentos possíveis.

Como resultados significativos, pode-se destacar que a análise estatística apontou que o IRDI como um todo possui uma capacidade maior de predizer problemas de desenvolvimento do que a capacidade de predizer risco psíquico ${ }^{4}$; quinze indicadores mostraram possuir a sensibilidade de indicar uma tendência em direção ao risco de entraves no processo de constituição do sujeito, sendo, portanto, indicativos de risco psíquico; indicadores de desenvolvimento psíquico foram incluídos na ficha de acompanhamento do Desenvolvimento de Crianças de zero a cinco anos proposta pelo Ministério da Saúde. 
É desse modo que, sem desconsiderar os vieses existentes em pesquisas que se propõem a trabalhar entre os campos da Psicanálise e da Saúde Pública, destacamos o que consideramos um dos resultados valiosos da pesquisa IRDI: o instrumento AP3.

Observamos que as contribuições diagnósticas da AP3 revelam seu valor em nossa prática clínica com crianças, e não hesitamos em lançar mão de tal instrumento em entrevistas iniciais, já que ele pode nos auxiliar na compreensão da dinâmica psíquica de uma família, por exemplo.

$\mathrm{E}$, como não poderia deixar de ser, já que temos claro interesse pela clínica psicanalítica com crianças, consideramos a importância das questões que a AP3 nos oferecem sobre o brincar e o estatuto da fantasia. Se, por meio do discurso, tem-se acesso às mais variadas fantasmatizações do sujeito $^{5}$, quando se trata de análise com crianças é preciso ressaltar que esse discurso vem atrelado à dimensão lúdica. É preciso que haja abertura para o brincar e, consequentemente, para as criações que ele possibilita. No universo infantil, um discurso pode ser uma história, um boneco pode ser o pai, uma casa pode ser um avião, uma caixa pode ser um telefone, de tal forma que uma coisa pode sempre remeter a outra, em uma série de infinitas possibilidades, cuja significação só adquire força quando alguém que lhe dá um contorno, transmitindo-lhe sentidos capazes de 
inscrevê-la em uma narrativa pessoal. Afinal, como já dissera Manoel de Barros em suas Memórias inventadas, “eu já sabia também que as palavras possuem no corpo muitas oralidades remontadas e muitas significâncias remontadas" (Barros, 2003).

A proposta inscrita neste trabalho diz respeito à possibilidade de identificar alguns sintomas clínicos na infância em um tempo que se pode dizer inicial, no sentido de que ainda há tempo de intervir. Tempo este da primeira infância, do brincar, das fantasias expressas em brincadeiras. Eis um ponto central de articulação entre o que se identifica como problemas de desenvolvimento e possibilidade de intervenção.

É importante ressaltar, contudo, que assim como a fantasia subjacente ao brincar infantil pode funcionar como um indício de que algo não vai bem e, consequentemente, pode sinalizar uma via possível de elaboração para um sintoma em questão, ela também guarda sua dimensão de indizível e de incapturável. Em outros termos, nem todo sintoma pode ser expresso/elaborado cabalmente. A respeito, Salztrager (2006) destaca um paradoxo interessante: a fantasia ora se presentifica como a resultante do extenso trabalho de representação psíquica, ora como o que, justamente, resiste à atividade representativa, de tal modo que a fantasia também comporta um núcleo indizível e inassimilável pela rede de significações.

E é essa dimensão de indizível, de algo que se configura como resíduo que escapa ao encadeamento significante, que aponta para um trabalho que não se esgota. Há de se lidar com aquilo que nos escapa, limite de nossas teorizações e pretensões de tudo-saber. Afinal, é preciso que se considere que todo dizível carrega sua dimensão de in-dizível, de in-capturável, de não dito.

Para finalizar, retomamos um trecho de Ítalo Calvino em que ele descreve Ipásia, uma de suas cidades invisiveis: "De todas as mudanças de língua que o viajante deve enfrentar em terras longínquas, nenhuma se compara à que o espera na cidade de Ipásias, porque não se refere às palavras mas às coisas.... Subi as escadas de pórfido do palácio que tinha as cúpulas mais altas, atravessei seis pátios de maiólica com chafarizes.... Só me restava interrogar os filósofos. Entrei na grande biblioteca, perdi-me entre as estantes que despencavam sob o peso de pergaminhos encadernados, segui a ordem alfabética de alfabetos extintos, para cima e para baixo pelos corredores, escadas e pontes. Na mais remota sala de papiros, numa nuvem de fumaça, percebi os olhos imbecilizados de um ado- 
lescente deitado numa esteira, que não tirava os lábios de um cachimbo de ópio.

- Onde está o sábio? - O fumador apontou para o lado de fora da janela. Era um jardim com brinquedos para crianças: os pinos, a gangorra, o pião. O filósofo estava sentado na grama. Disse:

- Os símbolos formam uma língua, mas não aquela que você imagina conhecer.

Compreendi que devia me liberar das imagens que até ali haviam anunciado as coisas que procurava: só então seria capaz de entender a linguagem de Ipásia.... Sem dúvida também em Ipásia chegará o dia em que o meu único desejo será partir. Sei que não devo descer até o porto mas subir o pináculo mais elevado da cidadela e aguardar a passagem de um navio lá em cima. Algum dia ele passará? Não existe linguagem sem engano." (Calvino, 2003, pp. 49-50).

CONSIDERATIONS ABOUT CHILDPLAY AND THE STATUTE OF FANTASY FROM THEORETICAL PROPOSITIONS THAT BASES THE IRDI RESEARCH

\section{Abstract}

This work was designed from the theme of childplay and the statute of fantasy, the theoretical axis of the AP3. It is proposed that the play as a developing route of a particular version concerning the significant related to the construction of the child's own body, to its Otherness and to the world that is presented, as well as the expression of the position of the child as a being in constitution and even a 
being that (already) is. In its relationship to fantasy - or as a means of phantasmatic expression - the play enables processes of representation and, paradoxically, points to something that resists being represented, although it continues to operate in the psychism.

Index terms: play; fantasy; child development; clinical indicators.

CONSIDERACIONES SOBRE EL JUGAR Y EL ESTATUTO DE LA FANTASÍA A PARTIR DE PROPOSICIONES TEÓRICAS QUE BASAN LA INVESTIGACIÓN IRDI

\section{RESUMEN}

Este trabajo fue diseñado desde el tema del jugar y el estatuto de la fantasía, eje teórico de la AP3. Se propone el jugar como un medio para elaborar una versión particular de los significantes relacionados a la construcción del propio cuerpo delniño, a su Otro y al mundo que se presenta a el, asi como expresión de la posición del niño como sujeto en constitución e incluso sujeto que (ya) es. En su relación con la fantasía - o como medio de expresión fantasmática -, el jugar permite procesos de representación y, paradójicamente, apunta a algo que se resiste a ser representado, pero sigue funcionando en la psique.

Palabras clave: juego; fantasía; desarrollo del niño; indicadores clínicos.

\section{REFERÊNCIAS}

Barros, M. (2003). Memórias inventadas: a primeira infância. São Paulo: Planeta.

Bernardino, L. M. F. (2006). A abordagem psicanalítica do desenvolvimento infantil e suas vicissitudes. In L. M. F. Bernardino (Org.), O que a psicanálise pode ensinar sobre a criança, sujeito em constituição. São Paulo: Escuta.

Calligaris, C. (1993). À escuta do sintoma social. Anuário Brasileiro de Psicanálise. 1(1), 11-23.

Calvino, I. (2003). As cidades invisiveis. São Paulo: Publifolha.

Freud, S. (1996a). Carta 69. In S. Freud, Obras psicológicas completas de Sigmund Freud (Vol. 1, pp. 301-303). Buenos Aires: Amorrortu. (Trabalho original publicado em 1897)

(1996b). Escritores criativos e devaneio. In S. Freud, Edição standard brasileira das obras psicológicas completas de Sigmund Freud (J. Salomão, trad., Vol. 9, pp. 133-143). Rio de Janeiro: Imago. (Trabalho original publicado em 1907)

Garcia-Roza, L. A. (2000). Freud e o inconsciente. Rio de Janeiro: Jorge Zahar.

Giongo, A. L. (2005). Histórias para brincar. Correio da APPOA. 136, 36-48.

Jerusalinsky, A. (2004). Psicanálise e desenvolvimento infantil: um enfoque transdisciplinar. (3a ed.). Porto Alegre, RS: Artes e Ofícios.

(2008). Considerações acerca da avaliação psicanalítica de crianças de 03 a 04 anos. In R. Lerner \& M. C. M. Kupfer (Orgs.), Psicanálise com crianças: clínica e pesquisa (pp. 117-136). São Paulo: Escuta.

Jorge, M. A. C. (2007). Lacan e a escrita da fantasia. In A. Costa \& D. Rinaldi, Escrita e psicanálise. Rio de Janeiro: Cia. de Freud/UERJ, Instituto de Psicologia. 
Kupfer, M. C. M., Bernardino, L. M. F., Jerusalinsky, A. N., Rocha, P. S., Lerner, R. et al. (2008). A pesquisa IRDI: resultados finais. In R. Lerner \& M. C. M. Kupfer (Orgs.), Psicanálise com crianças: clínica e pesquisa (pp. 221-230). São Paulo: Escuta.

Kupfer, M. C. M., Jerusalinsky, A. N., Bernardino, L. M. F., Wanderley, D., Rocha, P. S. B. et al. (2009). Valor preditivo de indicadores clínicos de risco para o desenvolvimento infantil: um estudo a partir da teoria psicanalítica. Latin American Journal of Fundamental Psychopathology Online, 6(1), 48-68.

Lacan, J. (1966-1967). Séminaire La logique du fantasme. Edição Interna da Associação Freudiana Internacional.

Rodulfo, R. (1990). O brincar e o significante: um estudo psicanalítico sobre a constituição precoce. Porto Alegre, RS: Artes Médicas.

Salztrager, R. (2006). Os paradoxos da fantasia. Interações, 11(21), 79-96.

Toledo, M. R. (2003). A fantasia e suas implicações na clínica psicanalítica. Dissertação de Mestrado, Departamento de Psicologia, Pontifícia Universidade Católica do Rio de Janeiro, Rio de Janeiro.

Víctora, L. G. (2005). O conceito de fantasma na obra de Lacan. Correio da APPOA, Porto Alegre, 138, 13-22.

Winnicott, D. W. (1975). O brincar e a realidade. Rio de Janeiro: Imago.

\section{NOTAS}

1 A pesquisa foi realizada pelo GNP, grupo de experts reunido para construir o protocolo de indicadores e para conduzir a pesquisa multicêntrica em seus diferentes centros. O grupo foi constituído por Leda M. Fischer Bernardino, da PUC de Curitiba, Paula Rocha e Elizabeth Cavalcante, do CPPL de Recife, Domingos Paulo Infante, Lina G. Martins de Oliveira e M. Cecília Casagrande, de São Paulo, Daniele Wanderley, de Salvador, Lea M. Sales, da Universidade Federal do Pará, Profa. Regina M. R. Stellin, da UNIFOR de Fortaleza, Flávia Dutra, de Brasília, Otavio Souza, do Rio de Janeiro, Silvia Molina, de Porto Alegre, com coordenação técnica de M. Eugênia Pesaro, coordenação científica de Alfredo Jerusalinsky e coordenação científica nacional de M. Cristina M. Kupfer.

2 O Outro primordial que, instaurado pela função materna (por um outro faltoso e, por isso, desejante), inscreve o sujeito na ordem da linguagem e da cultura. Tal instância carrega a possibilidade de marcar a falta na criança, viabilizando também, para o pequeno ser, a condição de sujeito desejante. Para nós, o Outro também guarda a capacidade de marcar uma diferença eu-outro, o que teria por consequência a instauração de possibilidades de constituição subjetiva no que refere ao aspecto estrutural.

3 Referida na afirmação de Calligaris.

4 Para os fins da pesquisa, considerou-se que problemas de desenvolvimento sinalizam a presença de dificuldades subjetivas que afetam ou incidem no desenvolvimento da criança sem questionar a instalação do sujeito psíquico. Risco psíquico, por sua vez, seria uma categoria que compreende as dificuldades de desenvolvimento sinalizadoras de entraves no processo mesmo de constituição subjetiva, 
apontando problemas mais estruturais, um risco de evolução em direção às psicopatologias graves da infância, tais como os chamados distúrbios globais do desenvolvimento (Kupfer et al., 2009).

5 É interessante pontuar uma breve diferenciação entre o fantasiar presente no brincar infantil, tema de nosso estudo, e a concepção do fantasma tal como definido por Lacan (1966-1967) no seminário sobre $A$ lógica do fantasma. Se o primeiro conceito é considerado fundador da cena psicanalítica propriamente dita, haja vista que remete à dimensão inconsciente e criativa do ser humano, o segundo é considerado uma teorização lacaniana que expressa uma formulação concernente à relação (inconsciente) do sujeito com seu objeto de desejo após o corte do significante/a palavra do Outro. A formulação da lógica do fantasma $(\$ \triangleright$ a) (onde se lê "sujeito barrado punção de pequeno a") expressa a fundação de um sujeito castrado e, portanto, desejante, que busca seu objeto de desejo sem o alcançar (por isso a queda do objeto a). Trata-se, em última instância, da relação do sujeito com seu objeto de desejo. A respeito, cf. Lacan (1966-1967); Víctora (2005).

angeladipaolo@usp.br carolinavalerio@usp.br

Recebido em dezembro/ 2009. Aceito em maio/ 2010. 